\title{
Stress-Strain and Failure Modes of Asphalt Concrete in Compression Due to Geometrical Changes
}

\author{
Lee P. Leon, $\mathrm{MSc}^{1}$, Derek Gay, $\mathrm{PhD}^{1}$, Nicola Simpson, $\mathrm{BSc}^{2}$ and Shian Edwin, $\mathrm{BSc}^{2}$ \\ ${ }^{1}$ University of The West Indies, Trinidad \& Tobago, lee.leon@sta.uwi.edu, derek.gay@sta.uwi.edu \\ ${ }^{2}$ University of The West Indies, Trinidad \& Tobago, simpsonanicola@gmail.com, shianedwin@live.com
}

\begin{abstract}
The stress- strain relationship of materials is used to predict their performance during service. This paper presents an evaluation of asphalt concrete modes of failure and describes the stress-strain relationship that governs the material beyond the limit of elasticity. The relationship of stress-strain is identical to that of cement concrete in compression. The experiments used short term static compression loading on cylindrical and prismatic asphalt concrete specimens. The effects of mixture types, specimen shape, height, temperature, binder type and testing orientation were investigated. The key parameters of the stress- strain curve were determined and used in assessing the failure mode, were: unconfined compressive strength, the strain at peak stress, initial tangent modulus and fracture energy. The tests revealed that cube specimens tested parallel to the direction compacted, achieved higher compressive strength than specimens tested perpendicular to the direction compacted. Similar strain at peak stress was obtained for both loading directions. An increase in height in cylindrical specimens, resulted in a decrease in compressive strength and strain at peak stress. Cylindrical specimens had greater stiffness than prismatic specimens with similar aspect ratios. Specimens at higher temperatures attained lower compressive strength. The study also showed that temperature has significant influence on the initial tangent modulus and fracture energy. The higher the temperature, the lower the initial tangent modulus and the fracture energy. There were significant changes in the peak stress and strains between the asphalt concrete mix types. The parameters derived can and have been used for inputs in finite element programs to model the laboratory and field behavior of different asphalt concrete mixtures used in pavement structures.
\end{abstract}

Keywords-- Stress-Strain, Asphalt Concrete, Elastic Modulus, Fracture Energy, Failure Modes, Compression

\section{INTRODUCTION}

Asphalt concrete (AC) is a composite material made up of different grades of aggregates bound together with bitumen (binder). When the aggregates and the binder are combined to produce asphalt concrete, new properties are undertaken by the mixture that is influenced by the individual components. Although asphalt concrete is extensively used as a pavement material over the world, literature on its stress-strain behaviour is limited compared to other commonly used materials, such as cement concrete and steel alloys.

Ref. [15] suggested that the behaviour of asphalt concrete under short term compression is identical to that of cement concrete and rock. The effect of shape and size of specimens on the compressive strength of cement concrete, and by extension the stress-strain relationship has been studied

Digital Object Identifier (DOI): http://dx.doi.org/10.18687/LACCEI2018.1.1.85 ISBN: 978-0-9993443-1-6

ISSN: $2414-6390$

$16^{\text {th }}$ LACCEI International Multi-Conference for Engineering, Education, and Technology: "Innovation in Education and Inclusion”, 18-20 July 2018, Lima, Peru. widely. Ref. [17] conducted research on the failure of concrete under uniaxial compression, where the results showed geometry had pronounced effects around the peak stress and post peak regime. Comparable research has not been conducted for asphalt concrete to validate similarities of the effects of geometry. Ref. [9] indicated that the failure stress and strain of asphalt concrete is influenced by the height of specimens, which had not been mentioned in previous research. They presented in Fig. 1, a schematic of the idealized stress strain curve of the elasto-plastic behavior of the material.

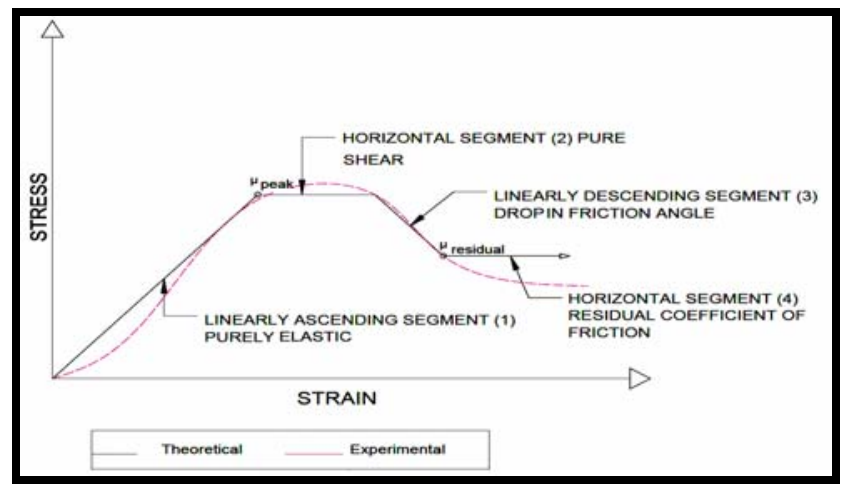

Fig. 1 Idealized stress-strain curve showing elastoplastic behavior, Ref. [9]

Compressive stress applied to asphalt concrete causes unbalanced forces in the system from which results in deformation, cracks and fatigue failure. These applications are useful in determining the plastic and elastic limits of AC. Plastic deformation and fatigue failure occur when the yield point of the material has been exceeded which is a problem seen in many $\mathrm{AC}$ pavements today, hence, a connection between the stress and strain in AC needs to be explored especially for the purpose of designing. This paper investigates the effects of shape, size and height of specimens, temperature, mix and binder type on the complete stress-strain behaviour of asphalt concrete.

Knowledge of the stress-strain behaviour of pavement materials can also enhance the development of more realistic design models. The parameters (such as the compressive strength, strain at peak strength and initial tangent modulus) derived, can be used in finite element programs to model the behaviour of different asphalt concrete mixtures used in pavement structures. 


\section{EXPERIMENTAL PROGRAM}

\section{A. Materials and Mix Design}

The common dense-graded and stone matrix asphalt mixture were used. Coarse aggregates were limestone and fine aggregates consists sharp sand and limestone dust. These aggregates were blended in accordance with their respective mixture requirements for a wearing course asphalt pavement layer. Two asphalt binders were used in the preparation of specimens; Trinidad Lake Asphalt (TLA) and modified refined bitumen with penetration grades of 60/70 and 60/75 respectively. The optimum binder contents were found to be $5.3 \%$ for the TLA and $5.0 \%$ for the modified refined bitumen.

\section{B. Specimens and Testing}

Cylindrical and cube specimens were used to generate the stress-strain curves. Two cylindrical specimen sizes; $100 \mathrm{~mm}$ x $100 \mathrm{~mm}$ and $100 \mathrm{~mm}$ x $150 \mathrm{~mm}$ (diameter x height) and one cube size with edges of $100 \mathrm{~mm}$ was used. To eliminate scatter in results, cube specimens were formed from saw cutting cylinders with dimensions $150 \mathrm{~mm}$ x $100 \mathrm{~mm}$ (diameter $\mathrm{x}$ height) to keep the compaction direction (vertical) constant for all specimens. All specimens were prepared using the gyratory compactor in accordance with BS EN 12697-31: 2007, with percent air voids of $7 \%$ with $\pm 1 \%$.

The specimens were tested under static uniaxial compression at a continuous loading rate of $24 \mathrm{~mm} / \mathrm{min}$. All cylindrical specimens were loaded parallel to the compaction direction; however, cube specimens were loaded both parallel and perpendicular to the compaction direction. The samples were tested at three temperatures: low $\left(20^{\circ} \mathrm{C}\right)$, ambient $\left(28^{\circ} \mathrm{C}\right)$ and high $\left(35^{\circ} \mathrm{C}\right)$, which mimic the temperatures asphalt pavements are exposed to in the tropical region.

\section{Data Analysis}

The principal parameters used to analyse the stress-strain curve were the peak stress, the strain at peak stress, the initial tangent modulus and the strain energy at ultimate failure. Each parameter was evaluated considering the effects of shape and height of the specimens, loading direction, temperature and type of binder. A stress-strain curve was generated from the average of a minimum of two specimens.

MATLAB was used as the main software for analyzing the data. Programming algorithm was used to determine all the key parameters of the stress-strain curve. Crack patterns and stress-strain curves were investigated to classify the type of failure. The effect of shape, size and height of the specimen on the compressive strength, the strain at peak stress, initial tangent modulus and strain energy at ultimate failure of asphalt concrete was determined by comparing the values obtained and by graphical interpretation of the data.

1) Stress-strain Curves: For each data set, the stressstrain curve for each individual specimen was plotted. For each individual stress-strain curve, stress values were interpolated for every $0.0001 \mathrm{~mm} / \mathrm{mm}$ strain. At each strain value, the average stress was calculated and a plot of strain versus average stress was plotted.

2) Initial Tangent Modulus and Correcting Curves for Seating Error: The ends of specimens are usually not plane, consequently the stress-strain curves would consist an initial bottom concave part representing the seating of the specimen. As a result, the curves required correction prior to the determination of the initial tangent modulus. The initial tangent modulus was determined using a linear fit to the data points satisfying the criteria to be considered within the elastic region. Data points prior to the point of peak stress, with an incremental gradient (gradient between consecutive data points) within $75 \%$ of the maximum incremental gradient were considered within the elastic region. This approach was used as the initial tangent modulus of asphalt concrete is highly sensitive to temperature changes. The linear fit was accepted if the coefficient of correlation was in exceedance of 0.99 .

3) Strain at Peak Stress and Compressive Strength: The stress value corresponding to the peak point on the average stress-strain curve was considered the compressive strength. The strain value corresponding to the peak point on the average stress-strain curve was considered the strain at peak stress.

4) Strain Energy at Ultimate Failure: In the study the strain energy at ultimate failure was taken to be the area beneath the stress-strain curve until the first inflection point on the descending branch of the stress-strain curve.

\section{RESULTS AND ANALYSIS}

\section{A. Failure Modes}

The failure modes of specimens are illustrated in Fig. 2. By visual analysis, cylindrical specimens with height $100 \mathrm{~mm}$ exhibited bulging failure, whereas the specimens $150 \mathrm{~mm}$ in height displayed shear failure. Cube specimens showed a combination of bulging failure and cracks concentrated near the corners of the cubes. It was observed that there was no lateral strain at the ends of specimens.

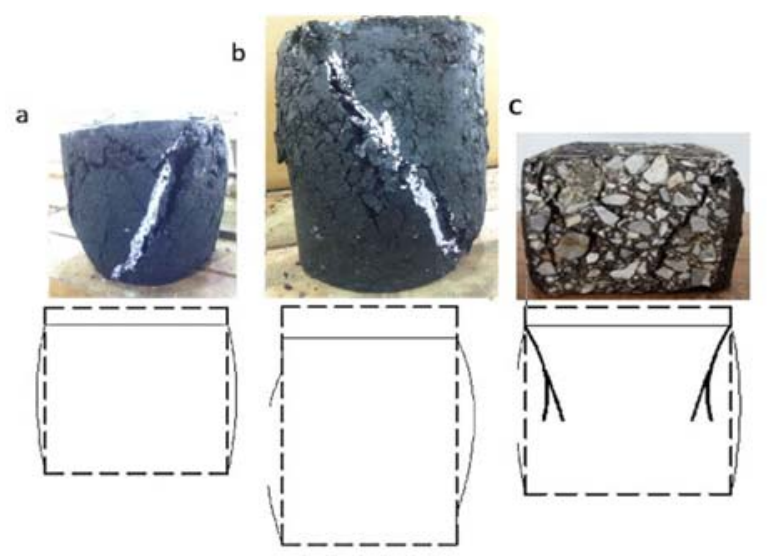

Fig. 2 Failure modes of test specimens (a) 100mm height, (b) $150 \mathrm{~mm}$ height (c) $100 \mathrm{~mm}$ cube

$16^{\text {th }}$ LACCEI International Multi-Conference for Engineering, Education, and Technology: "Innovation in Education and Inclusion", 18-20 July 2018, Lima, Peru. 


\section{B. Mohr Coulomb Behavior of Asphalt Concrete Mixes}

The Mohr-Coulomb law is a law linearly relating the shear to the normal stress. This line is a yielding condition for shearing. Below this yield line, the material response will be rigid and does not suffer any strain. If the shear stress is increased for a given normal stress such that the stress state of the material is exactly on the yield line, then plastic strain or yielding will result. The average failure (shear) angles for all mix types were measured to be an average angle of $\beta=70^{\circ}$. The Mohr's Coulomb Circle was used to validate this failure angle to be associated with the mode of failure as being true shear failure. The failure (shear) angle and the maximum axial (major principal) stress were used to calculate friction angle $(\phi)$. This value could also be obtained by the use of the derived Mohr's Circle equation which is:

$$
2 \beta=90^{0}+\phi
$$

The friction value was average to be $50^{\circ}$ as presented in Table I. This angle is similar to that of crushed rock, and this is sufficient since the mixes were made of crushed limestone. Since this relationship can be represented by the MohrCoulomb Failure Criteria, the failure mode is in fact shear failure.

TABLE I

SHEAR FAILURE AND FRICTION ANGLES OF ASPHALT CONCRETE MiXES

\begin{tabular}{|l|c|c|}
\hline \multicolumn{1}{|c|}{ Mix Type } & $\begin{array}{c}\text { Average Measured } \\
\text { Failure Angle }(\beta)\end{array}$ & $\begin{array}{c}\text { Calculate Friction } \\
\text { Angle }(\phi)\end{array}$ \\
\hline TLA Mixes & 69 & 50 \\
\hline Refined Bitumen Mixes & 70 & 51 \\
\hline Stone Matrix Mixes & 68 & 48 \\
\hline
\end{tabular}

\section{Stress-Strain Curve}

The stress-strain relationship of specimens essentially comprised an ascending and descending branch. All specimens showed similar curve patterns irrespective of mix and binder type, loading direction, temperature, shape and height of specimen. The stress-strain curves of TLA and modified refined bitumen cubes specimens are shown in Fig. 3 and Fig. 4. The compressive strength, strain at peak stress, initial tangent modulus and strain energy at ultimate failure for cube specimens loaded parallel (par.) and perpendicular (perp.) to the compaction direction are presented in Tables II and III. The stress-strain curves of the TLA and modified refined bitumen (M.R.B.) cylindrical specimens are shown in Fig. 5 and Fig. 6. The compressive strength, strain at peak stress, initial tangent modulus and strain energy at ultimate failure for cylindrical specimens of height $100 \mathrm{~mm}(\mathrm{H} 1)$ and $150 \mathrm{~mm}(\mathrm{H} 2)$ are presented in Tables IV and V.

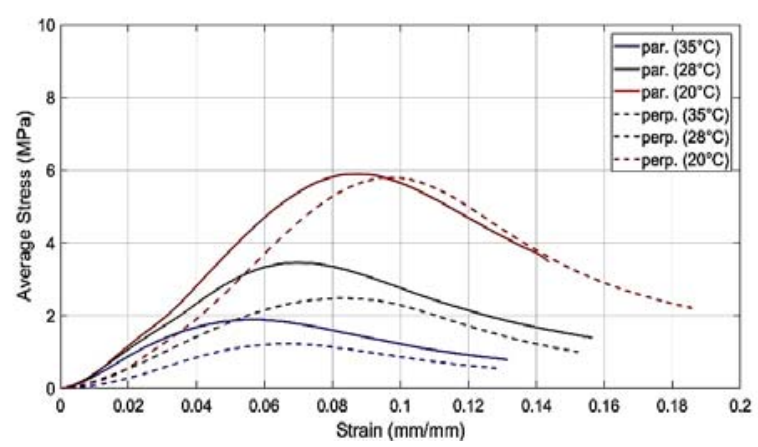

Fig. 3 Stress-strain Curves for TLA Binder Cubes

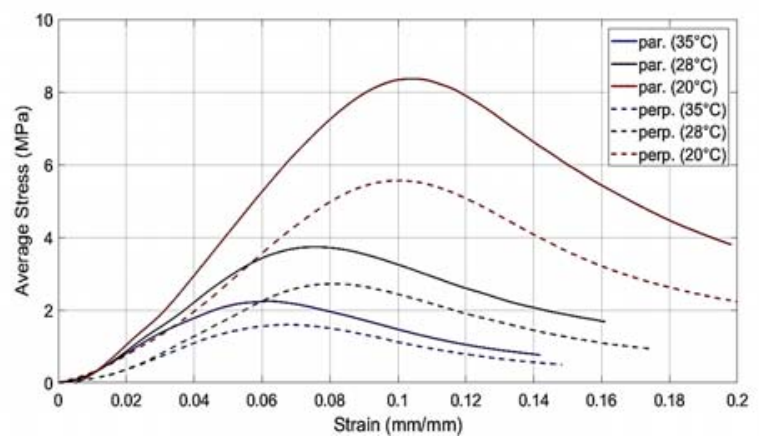

Fig. 4 Stress-strain Curves for Modified Refined Bitumen Cubes

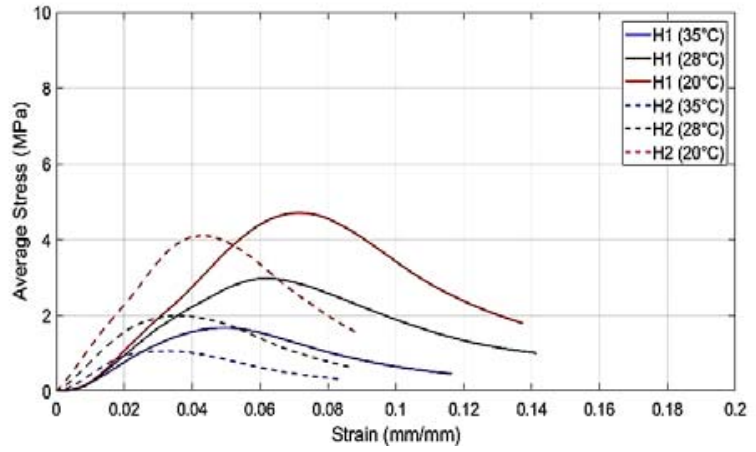

Fig. 5 Stress- strain Curves for TLA Binder Cylinders

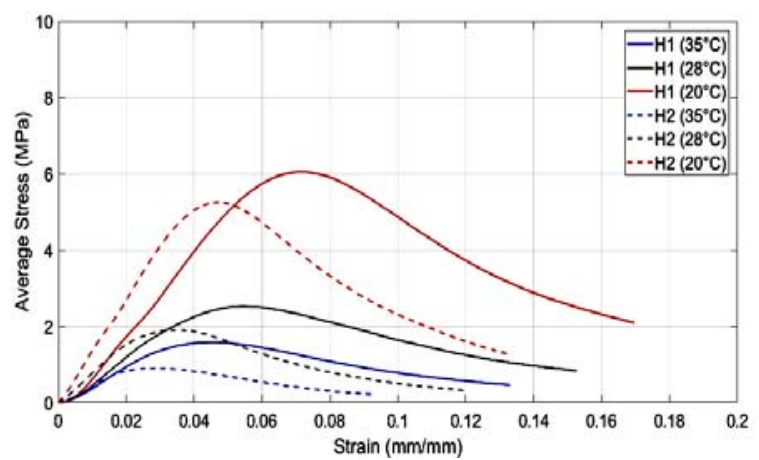

Fig. 6 Stress-strain Curves for Modified Refined Bitumen Cylinders

$16^{\text {th }}$ LACCEI International Multi-Conference for Engineering, Education, and Technology: "Innovation in Education and Inclusion", 18-20 July 2018, Lima, Peru. 
TABLE II

Cube SPECIMENS LOADED PARALLEL TO COMPACTION DiRECTION

\begin{tabular}{|c|c|c|c|c|c|c|}
\hline \multirow{2}{*}{ Binder Type } & \multirow{2}{*}{$\begin{array}{c}\text { Testing } \\
\text { Temperature } \\
\left({ }^{\circ} \mathrm{C}\right)\end{array}$} & \multirow{2}{*}{$\begin{array}{l}\text { Compressive Strength } \\
\text { (MPa) }\end{array}$} & \multirow{2}{*}{$\begin{array}{l}\text { Initial Tangent } \\
\text { Modulus (MPa) }\end{array}$} & \multirow{2}{*}{$\begin{array}{c}\text { Strain at Peak } \\
\text { Stress }(\mathrm{mm} / \mathrm{mm})\end{array}$} & \multicolumn{2}{|c|}{ Strain Energy at Ultimate Failure } \\
\hline & & & & & $\left(\mathrm{x} 10^{5} \mathrm{Jm}^{-3}\right)$ & (MPa) \\
\hline TLA & 20 & 5.9 & 88.3 & 0.0800 & 4.42 & 0.442 \\
\hline TLA & 28 & 3.5 & 63.5 & 0.0662 & 2.27 & 0.227 \\
\hline Modified Refined Bitumen & 28 & 3.7 & 67.8 & 0.0684 & 2.56 & 0.256 \\
\hline TLA & 35 & 1.9 & 53.0 & 0.0528 & 1.13 & 0.113 \\
\hline Modified Refined Bitumen & 35 & 2.2 & 56.3 & 0.0565 & 1.36 & 0.136 \\
\hline
\end{tabular}

TABLE III

Cube SPECIMENS LOADED PERPENDICULAR TO COMPACTION DiRECTION

\begin{tabular}{|c|c|c|c|c|c|c|}
\hline Binder Type & $\begin{array}{c}\text { Testing } \\
\text { Temperature } \\
\left({ }^{\circ} \mathrm{C}\right)\end{array}$ & $\begin{array}{l}\text { Compressive Strength } \\
\text { (MPa) }\end{array}$ & $\begin{array}{l}\text { Initial Tangent } \\
\text { Modulus (MPa) }\end{array}$ & $\begin{array}{c}\text { Strain at Peak } \\
\text { Stress }(\mathrm{mm} / \mathrm{mm})\end{array}$ & \multicolumn{2}{|c|}{$\begin{array}{c}\text { Strain Energy at Ultimate Failure } \\
(\mathrm{MPa})\end{array}$} \\
\hline TLA & 20 & 5.8 & 89.7 & 0.0776 & 4.27 & 0.427 \\
\hline TLA & 28 & 2.5 & 42.6 & 0.0752 & 1.88 & 0.188 \\
\hline Modified Refined Bitumen & 28 & 2.7 & 48.4 & 0.0673 & 1.82 & 0.182 \\
\hline TLA & 35 & 1.2 & 28.6 & 0.0556 & 0.71 & 0.071 \\
\hline
\end{tabular}

TABLE IV

100 MM HIGH CYLINDRICAL SPECIMENS

\begin{tabular}{|c|c|c|c|c|c|c|}
\hline \multirow[t]{2}{*}{ Binder Type } & \multirow{2}{*}{$\begin{array}{c}\text { Testing } \\
\text { Temperature } \\
\left({ }^{\circ} \mathrm{C}\right)\end{array}$} & \multirow{2}{*}{$\begin{array}{l}\text { Compressive Strength } \\
\text { (MPa) }\end{array}$} & \multirow{2}{*}{$\begin{array}{l}\text { Initial Tangent } \\
\text { Modulus (MPa) }\end{array}$} & \multirow{2}{*}{$\begin{array}{l}\text { Strain at Peak Stress } \\
(\mathrm{mm} / \mathrm{mm})\end{array}$} & \multicolumn{2}{|c|}{$\begin{array}{l}\text { Strain Energy at Ultimate Failure } \\
(\mathrm{MPa})\end{array}$} \\
\hline & & & & & $\left(\mathrm{x} 10^{5} \mathrm{Jm}^{-3}\right)$ & $(\mathrm{MPa})$ \\
\hline TLA & 20 & 4.7 & 86.5 & 0.0635 & 2.73 & 0.273 \\
\hline TLA & 28 & 3.0 & 71.2 & 0.0547 & 1.70 & 0.170 \\
\hline Modified Refined Bitumen & 28 & 2.5 & 72.2 & 0.0507 & 1.52 & 0.152 \\
\hline TLA & 35 & 1.7 & 53.8 & 0.0434 & 0.78 & 0.078 \\
\hline
\end{tabular}

TABLE V

150 MM HIGH CYLINDRICAL SPECIMENS

\begin{tabular}{|c|c|c|c|c|c|c|}
\hline \multirow{2}{*}{ Binder Type } & \multirow{2}{*}{$\begin{array}{c}\text { Testing } \\
\text { Temperature } \\
\left({ }^{\circ} \mathrm{C}\right)\end{array}$} & \multirow{2}{*}{$\begin{array}{c}\text { Compressive Strength } \\
\text { (MPa) }\end{array}$} & \multirow{2}{*}{$\begin{array}{l}\text { Initial Tangent } \\
\text { Modulus (MPa) }\end{array}$} & \multirow{2}{*}{$\begin{array}{c}\text { Strain at Peak } \\
\text { Stress }(\mathrm{mm} / \mathrm{mm})\end{array}$} & \multicolumn{2}{|c|}{$\begin{array}{c}\text { Strain Energy at Ultimate Failure } \\
(\mathrm{MPa})\end{array}$} \\
\hline & & & & & $\left(\mathrm{x} 10^{5} \mathrm{Jm}^{-3}\right)$ & $(\mathrm{MPa})$ \\
\hline Modified Refined Bitumen & 20 & 5.2 & 138.8 & 0.0463 & 2.45 & 0.245 \\
\hline TLA & 28 & 2.0 & 85.6 & 0.0346 & 0.88 & 0.088 \\
\hline Modified Refined Bitumen & 28 & 1.9 & 82.0 & 0.0338 & 0.76 & 0.076 \\
\hline
\end{tabular}

\section{Compressive Strength}

Specimens tested parallel to the compaction direction achieved higher compressive strength than specimens tested perpendicular to the compaction direction (Fig. 7). Similar compressive strength was attained by specimens of both binders for each loading direction (Fig 7). These trends were noticed for all temperatures, except for the low temperature, where TLA specimens achieved a similar strength for both loading directions and the compressive strength of the TLA and modified refined bitumen (M.R.B) specimens tested parallel to the compaction direction differed substantially. Ref. [1] stated that the compressive strength of asphalt concrete is provided from the resistance of the aggregate, resulting from the aggregate interlocking and the stiffness of the asphalt cement. Their research also indicated that the orientation of the aggregate could be influenced by compaction, hence the resistance to the applied compressive load provided by the aggregate interlocking could vary. As a result, the material

$16^{\text {th }}$ LACCEI International Multi-Conference for Engineering, Education, and Technology: "Innovation in Education and Inclusion", 18-20 July 2018, Lima, Peru. 
properties could vary for the different axes of the material. It was also claimed in their research that due to the vertical compaction (longitudinal axis) of the specimens, the aggregates in the asphalt concrete mixture tend to rotate parallel to horizontal direction. The change in the orientation of the aggregates may have attributed to the greater resistance when tested parallel to the compaction direction, due to the aggregate interlocking

For both binders, the compressive strength of cube specimens was consistently higher than that of cylindrical specimens with similar aspect ratios. When a specimen is subjected to pure uniaxial compressive forces, it expands in the trans-verse (lateral) direction, due to the poisson effect (in compression). A specimen tested under a uniaxial compression test, however, is not subjected to pure uniaxial compressive stress due to the development of friction between the steel platens of the testing machine and the ends of the asphalt concrete specimen. This frictional force is induced at the ends of the specimen due to the disparity between the elastic modulus and poisson ratio of steel and asphalt concrete. It also prevents lateral expansion at the ends of the specimen, which can be seen in Fig. 2 for all specimens irrespective of the height and shape. The frictional force produces lateral stresses essentially acting as a confining pressure causing a portion of the specimen to be in a state of triaxial stresses (undamaged zones). The effect of these lateral stresses is greatest at the ends of the specimens and decreases progressively toward the center of the specimen. The region of the specimen affected by these confining stresses is dependent on the geometry (shape and size) of the specimen. For cube specimens, there is a greater area of the specimen in contact with the platens of the machine, resulting in the entire specimen being affected the confining stresses. Consequently, cube specimens registered higher compressive strength than a cylindrical specimen of similar diameter and height.

Specimens $100 \mathrm{~mm}$ in height attained higher compressive strength than specimens $150 \mathrm{~mm}$ in height for both binders (Fig. 8). Relatively similar strength was obtained by specimens of both binders for each specimen height, except at the low temperature, where the modified refined bitumen specimens achieved higher compressive strength than TLA specimens of similar height (Fig. 8). For cylindrical specimens with a length to diameter ratio of less than or equal to one, restrained zones are created. However, for length to diameter ratios greater than one, restrained zones are formed at the two ends of the specimens, but an unrestrained zone at the central region of the specimen. Consequently, cylindrical specimens $100 \mathrm{~mm}$ in height specimens exhibited greater strength than the $150 \mathrm{~mm}$ specimens, as the length to diameter ratios for $100 \mathrm{~mm}$ and $150 \mathrm{~mm}$ specimens were 1 and 1.5 respectively.

The compressive strength of asphalt concrete decreases with increasing temperature (Fig. 7 and Fig.8). Asphalt concrete behaves like an elastoplastic material under compression due to the viscoelastic and plastic properties of the binder and aggregates respectively [9]. The viscosity of asphalt concrete is sensitive to temperature due to the influences of the binder. At ambient and elevated temperatures, the binder softens and reduces the viscosity of asphalt concrete. This makes asphalt concrete more susceptible to deformation as its ability to be compressed is increased, resulting in lower strength.

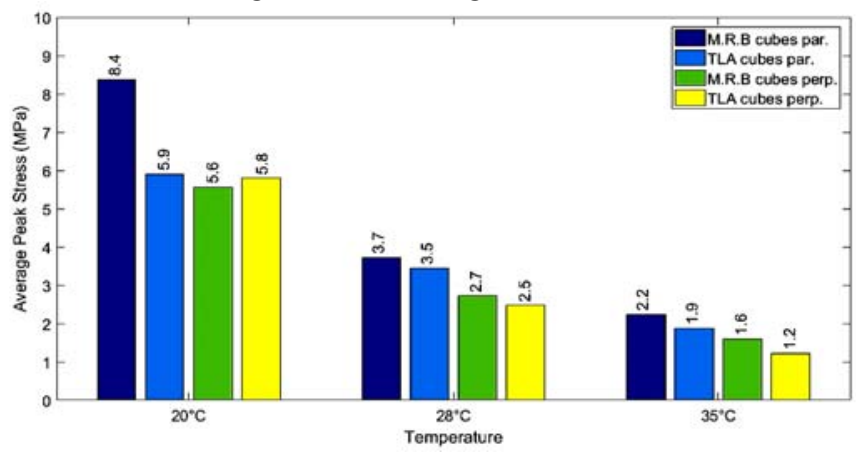

Fig. 7 Effects of Loading Direction, Binder Type and Temperature on the Compressive Strength of Asphalt Concrete

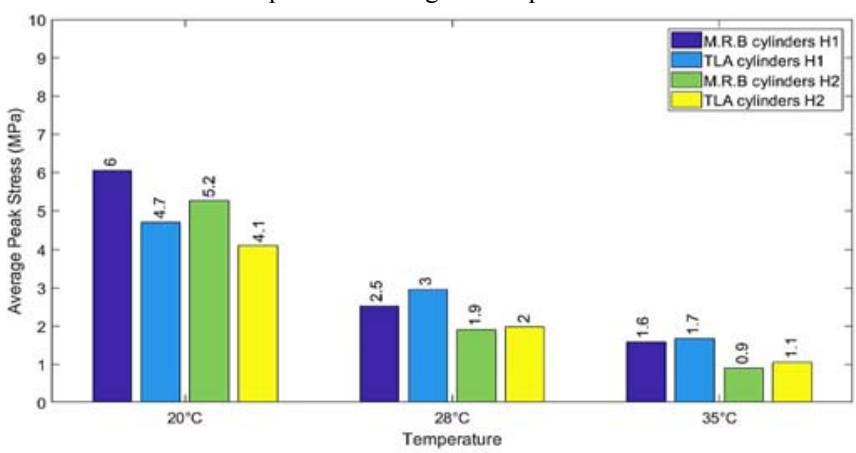

Fig. 8 Effects of Height of Specimen, Binder Type and Temperature on the Compressive Strength of Asphalt Concrete

The study also revealed that the effect of the binder type on the compressive strength of concrete is influenced by the testing temperature. At the ambient and high temperatures, the effect of the binder type on the compressive strength of asphalt concrete was insignificant. This indicates that at these temperatures, the two binders may have exhibited similar stiffness. All specimens were of the same design mix and by extension aggregate gradation, thus a similar resistance to the applied load would have been provided by the aggregates of the specimens, hence specimens would attain similar compressive strength. At the low temperature, however, there was no clear trend of the behaviour of the two binders and only speculations can be made.

\section{E. Strain at Peak Stress}

Similar strain values at peak stress were obtained for both loading directions for each binder type (Fig. 9). Similar strain values at peak stress were obtained irrespective of the binder type and loading direction, except at the low temperature. This indicates that the effect of the loading direction (anisotropic properties) of asphalt concrete may have major influence on the strain at peak stress. The strain at peak stress for the 100

$1^{\text {th }}$ LACCEI International Multi-Conference for Engineering, Education, and Technology: "Innovation in Education and Inclusion", 18-20 July 2018, Lima, Peru. 
$\mathrm{mm}$ high specimens were consistently higher than that of the $150 \mathrm{~mm}$ high specimens (Fig. 10). This effect just demonstrates that smaller samples fail at greater strains as these samples can endure more stress. Comparable strain values were obtained for both binders, for each sample height, which indicates that the height of specimen and temperature have a significant effect on the strain at peak stress, while the influence of the type of binder is negligible. Cube specimens registered higher strain at peak stress than cylindrical specimens (Fig. 9 and Fig. 10). The higher values of strain at peak stress for prismatic specimens may have been due to the confinement provided by the extra volume of concrete to constitute a square cross-section [11]. The strain at peak stress decreased with increasing temperature.

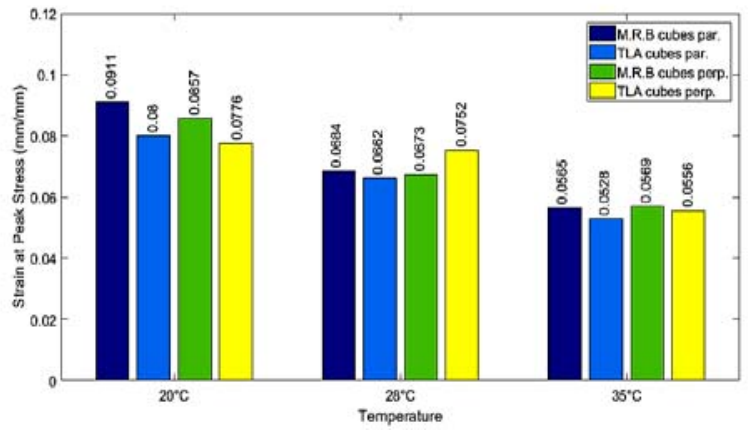

Fig. 9 Effects of Loading Direction, Binder Type and Temperature on the Strain at Peak Stress of Asphalt Concrete

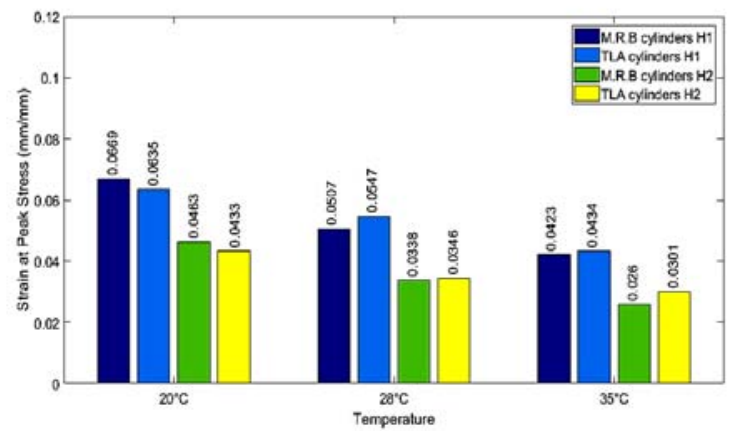

Fig. 10 Effects of Height of Specimen, Binder Type and Temperature on the Strain at Peak Stress of Asphalt Concrete

\section{F. Initial Tangent Modulus}

The initial tangent modulus was plotted against the respective testing temperature for the TLA and the modified refined bitumen specimens in Fig. 11 and Fig. 12 respectively. For the analysis, best- fit lines were used for the two specimen heights and testing orientation for each binder. It was depicted that $150 \mathrm{~mm}$ high cylindrical specimens exhibited higher initial tangent modulus values than the $100 \mathrm{~mm}$ high cylindrical specimens for both binders.

The cylindrical specimens $100 \mathrm{~mm}$ high cylindrical exhibited higher elastic modulus values than the $100 \mathrm{~mm}$ cubes specimens tested in a similar orientation (parallel to the compaction direction) for both binders. The difference in response observed in the stress-strain curves for cubes and cylinders is associated with the fracture process [7]. The fracture process of cubes is influenced by a stress concentration near the cube corners, which results in cracking near the cube corners.

For both binders, the initial tangent modulus of the cube specimens tested parallel to the compaction direction was greater than that of identical specimens tested perpendicular to the compaction direction. This may have been due to the anisotropic properties of asphalt concrete. The initial tangent modulus decreased with increasing temperature, which resulted due to the change in properties of bitumen because of temperature.

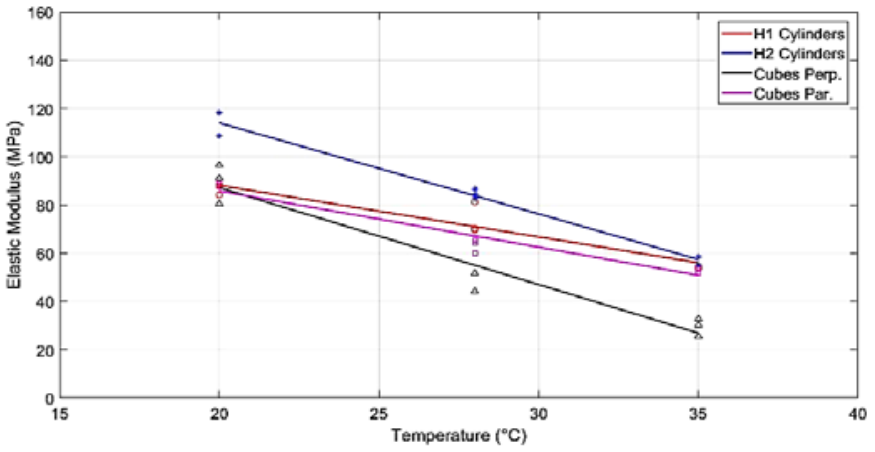

Fig. 11 Initial Tangent Modulus as a Function of Temperature for TLA Specimens

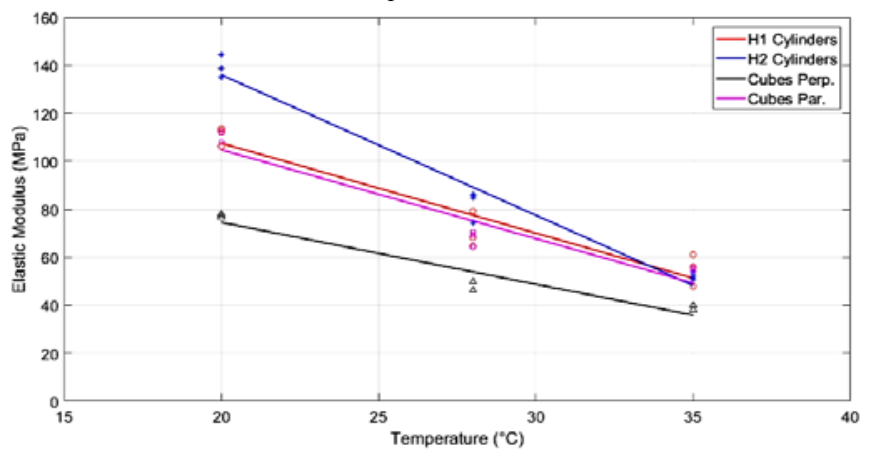

Fig. 12 Initial Tangent Modulus as a Function of Temperature for Modified Refined Bitumen Specimens

\section{G. Strain Energy at Ultimate Failure}

The absorption of energy per unit volume at ultimate failure is a measure of toughness. The study revealed that cube specimens depicted more toughness than cylindrical specimens (Fig. 13 and Fig. 14). It was also indicated that lower specimens exhibited greater toughness than taller specimens (Fig. 13). At any specific strain values, the corresponding stress value for the lower specimens is higher than that of the taller specimens. For this reason, the toughness of the $100 \mathrm{~mm}$ high specimens would be greater than that of the $150 \mathrm{~mm}$ high specimens.

Specimens loaded parallel to the compaction direction absorbed more energy at ultimate failure than specimens loaded perpendicular to the compaction direction (Fig. 13) due to the anisotropic properties of asphalt concrete. For both binders, specimens tested at the same orientation absorbed

16 $^{\text {th }}$ LACCEI International Multi-Conference for Engineering, Education, and Technology: "Innovation in Education and Inclusion", 18-20 July 2018, Lima, Peru. 
similar energy at all temperatures, except at the low temperature, where there was a considerable difference between the energy absorbed by the two binders for specimens tested parallel to the compaction direction. The reason for this trend was unable to be determined by the mechanical properties investigated in the study.

The toughness of asphalt concrete decreased with increasing temperature. The cause of this effect, may be similar to the effect of temperature on the compressive strength.

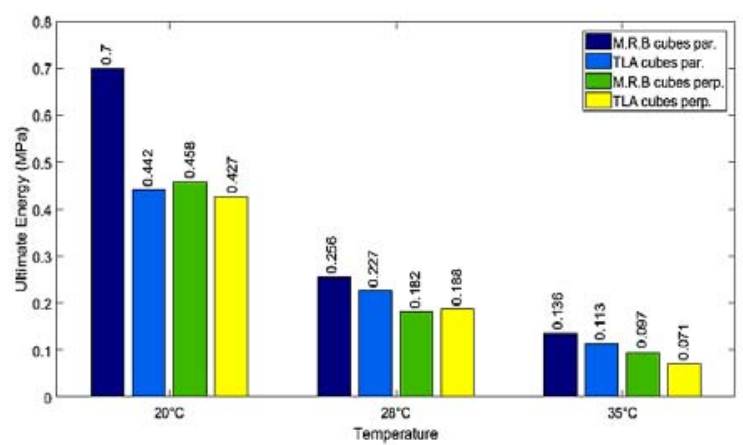

Fig.13 Effects of Loading Direction, Binder Type and Temperature on the Strain Energy at Ultimate Failure of Asphalt Concrete

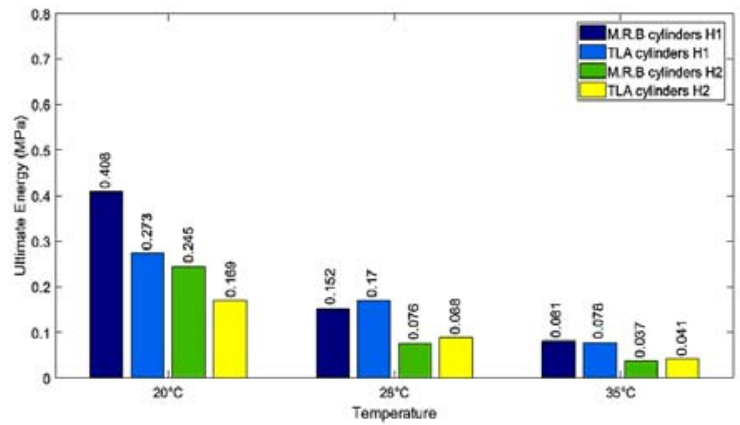

Fig. 14 Effects of Height of Specimen, Binder Type and Temperature on the Strain Energy at Ultimate Failure of Asphalt Concrete

TABLE VI

SUMMARY OF EFFECTS OF SPECIMEN HEIGHT, SHAPE, TEMPERATURE, MIX \& BINDER TYPE

\begin{tabular}{|l|c|c|c|c|c|c|}
\hline $\begin{array}{l}\text { Stress } \\
\text { strain } \\
\text { Parameter }\end{array}$ & Height & Shape & $\begin{array}{c}\text { Loading } \\
\text { Direction }\end{array}$ & Temp. & $\begin{array}{c}\text { Type } \\
\text { of } \\
\text { Binder }\end{array}$ & $\begin{array}{c}\text { Mix } \\
\text { Type }\end{array}$ \\
\hline $\begin{array}{l}\text { Comp. } \\
\text { Strength }\end{array}$ & Yes & Yes & Yes & Yes & $\begin{array}{c}\text { No } \\
\text { clear } \\
\text { trend }\end{array}$ & Yes \\
\hline $\begin{array}{l}\text { Strain at } \\
\text { Peak } \\
\text { Stress }\end{array}$ & Yes & Yes & No & Yes & $\begin{array}{c}\text { No } \\
\text { clear } \\
\text { trend }\end{array}$ & $\begin{array}{c}\text { No } \\
\text { clear } \\
\text { trend }\end{array}$ \\
\hline $\begin{array}{l}\text { Initial } \\
\text { Tangent } \\
\text { Modulus }\end{array}$ & Yes & Yes & Yes & Yes & $\begin{array}{c}\text { No } \\
\text { clear } \\
\text { trend }\end{array}$ & Yes \\
\hline $\begin{array}{l}\text { Strain } \\
\text { Energy at } \\
\text { Ultimate } \\
\text { Failure }\end{array}$ & Yes & Yes & Yes & Yes & $\begin{array}{c}\text { No } \\
\text { clear } \\
\text { trend }\end{array}$ & $\begin{array}{c}\text { No } \\
\text { clear } \\
\text { trend }\end{array}$ \\
\hline
\end{tabular}

\section{CONCLUSIONS}

If an asphalt mixture deforms (ruts) and exhibits fatigue failure, it is normally because the mixture has insufficient shear strength to support the stresses to which it is subjected. Aggregates are responsible for minimizing shear failure within an asphalt concrete mix. By subjecting asphalt concrete mixes in the form of cylinders and cubes to unconfined uniaxial compression testing, the failure mode of asphalt concrete was determined to be shear failure.

The effects of geometry on the stress-strain behaviour of asphalt concrete were investigated using uniaxial compression tests. The theories of the stress-strain properties of asphalt concrete which were formulated by different researchers proved to be true, in that there is a common pattern in the stress-strain graphs obtained from the results. A common pattern in the stress-strain graphs was identified irrespective of the specimen's geometry: initial bottom concave part, an ascending branch followed by a descending branch. Taller cylindrical specimens achieved lower compressive strength as well as lower corresponding strains at peak stress but gave higher initial tangent modulus than shorter specimens. Cube specimens attained higher compressive strength as well as higher corresponding strains at peak stress but gave lower initial tangent modulus than cylindrical specimens. Specimens tested parallel to the compaction direction exhibited greater strength, initial tangent modulus and strain energy at ultimate failure compared to specimens tested perpendicular to the compaction direction. There was no clear trend of the influences of loading direction on the strain at peak stress.

Other trends included the effect of temperature and the binder on the stress-strain behaviour of asphalt concrete. As temperature increased, the compressive strength, strain at peak stress, initial tangent modulus and strain energy at failure decreased. The influence of the mechanical properties of the binders on the stress-strain behaviour was not clear in the study and may be due to the difference in the chemical composition of the binders. As a result, it is proposed that research be pursued to investigate the influences of chemical composition of bitumen on the mechanical properties of asphalt concrete.

The trends highlighted in the research were identical to that of the effects of geometry and temperature on the stressstrain behaviour of high strength concrete, except for the effect of the loading direction on the strain at peak stress. For high strength concrete, the loading direction influences the strain at peak stress, however it was revealed in the study that loading direction has no considerable influence on the strain at peak stress.

The stress-strain parameters (initial tangent modulus, strain at peak stress and compressive strength) derived from the study can be used as input parameters in pavement modelling programs to model and simulate the behaviour (both elastic and plastic) of asphalt concrete, which is an integral part of design and evaluation of pavement structures.

$16^{\text {th }}$ LACCEI International Multi-Conference for Engineering, Education, and Technology: "Innovation in Education and Inclusion”, 18-20 July 2018, Lima, Peru. 
Finite element programs such as Abaqus, uses elastic as well as plastic data to model and simulate the visco-elastic-plastic behaviour of different mix types of asphalt concrete material used in a pavement structures.

\section{ACKNOWLEDGMENT}

We would like to recognize the scientific guidance and discussions of senior lecturer and researcher, the late Mr. Raymond Charles. The completion of this project would not have been possible without the support of the Highway Engineering and Structures Laboratories of the Civil and Environmental Department.

\section{REFERENCES}

[1] Alfoul, Bilal A. Abu, and Mohammad Khasawneh. 2006. "Laboratory Investigation of Anisotropic Behaviour of Hma." 2006 International Conference on Perpetual Pavement

[2] ASTM (American Society for Testing and Materials). 2016. ASTM C39/ C39M- 16b: Standard Test Method for Compressive Strength of Cylindrical Concrete Specimens. Pennsylvania: ASTM International.

[3] ASTM (American Society for Testing and Materials). 2017. ASTM D3203 / D3203M - 17: Standard Test Method for Percent Air Voids in Compacted Asphalt Mixtures. Pennsylvania: ASTM International.

[4] BSI (British Standards Institution). 2009. BS EN 12390- 3: 2009: Testing Hardened Concrete- Part 3: Compressive Strength of Test Specimens. London: BSI.

[5] BSI (British Standards Institution). 2007. BS EN 12697- 31: 2007: Bituminous Mixtures- Test Methods for Hot Mix Asphalt- Part 31: Specimen Preparation by Gyratory Compactor. London: BSI.

[6] BSI (British Standards Institution). 2004. BS EN 12697- 34: 2004: Bituminous Mixtures- Test Methods for Hot Mix Asphalt- Part 34: Marshall Test. London: BSI.

[7] Del Viso, J. R., J. R. Carmona, and G. Ruiz. 2008. "Shape and Size Effects on the Compressive Strength of High-Strength Concrete." Cement and Concrete Research 38 (3):386-395. doi: https://doi.org/10.1016/j.cemconres.2007.09.020.

[8] Jiao, Yubo, Hanbing Liu, Xianqiang Wang, Yuwei Zhang, Guobao Luo, and Yafeng Gong. 2014. "Temperature Effect on Mechanical Properties and Damage Identification of Concrete Structure." Advances in Materials Science and Engineering 2014:10. doi: 10.1155/2014/191360.

[9] Leon, Lee, Raymond Charles, and Nicola Simpson. 2016. "Stress-Strain Behaviour of Asphalt Concrete in Compression." Procedia Structural Integrity 2:2913-2920. doi: http://dx.doi.org/10.1016/j.prostr.2016.06.364.

[10]Mansur, M. A., M. S. Chin, and T. H. Wee. 1997. "Effects of Shape, Size, and Casting Direction of Specimens on Stress-Strain Curves of HighStrength Concrete." Materials Journal 94 (3). doi: 10.14359/301.

[11]Mansur, M. A., M. S. Chin, and T. H. Wee. 1999. "Stress-Strain Relationship of High-Strength Fiber Concrete in Compression." Journal of Materials in Civil Engineering 11 (1):21-29. doi: doi:10.1061/(ASCE)0899-1561(1999)11:1(21).

[12]Sarsam, Kaiss F., Tareq S. AL-Attar, and Mohammed M. Al-Saqi. 2014. "Effect of Height to Diameter Ratio on the Behaviour of High Performance Concrete Specimen with Different Shapes under Compression Load." Engineering and Technical Journal 33 (11):27342744.

[13]Seko, Shigeki, Sumie Suzuki, Yasij Ito, and Jadatsugu Kage. 2010. "Effect of Fracture Behavior and Height-to-Diameter Ratio on HighStrength Concrete Core Specimens' Compressive Strength." 7th International Conference on Fracture Mechanics of Concrete and Concrete Structures.

[14]Shoukry, Samir N., Gergis W. William, Brian Downie, and Mourad Y. Riad. 2011. "Effect of Moisture and Temperature on the Mechanical Properties of Concrete." Construction and Building Materials 25 (2):688696. doi: https://doi.org/10.1016/j.conbuildmat.2010.07.020.
[15]Starodubsky, S., I. Blechman, and M. Livneh. 1994. "Stress-Strain Relationship for Asphalt Concrete in Compression." Materials and Structures 27 (8):474-482. doi: 10.1007/bf02473452.

[16]Van Mier, et al. 1997. "Strain-Softening of Concrete in Uniaxial Compression." Materials and Structures 30 (4):195-209. doi: 10.1007/BF02486177.

[17]Van Mier, Johannes G. W 1998. "Failure of Concrete under Uniaxial Compression: An Overview." Fracture Mechanics of Concrete Structures 2:1169-1182.

[18]Wang, Jingang, André A. A. Molenaar, Martin F. C. van de Ven, and Shaopeng Wu. 2015. "Behaviour of Asphalt Concrete Mixtures under Triaxial Compression." Construction and Building Materials 105:269274. doi: http://dx.doi.org/10.1016/j.conbuildmat.2015.12.036.

[19]Wang, L. B., L. R. Hoyos, J. Wang, G. Voyiadjis, and C. Abadie. 2004. "Anisotropic Properties of Asphalt Concrete: Characterization and Implementation in Pavement Design and Analysis." 83rd Transportation Research Board Annual Meeting.

[20]Yi, Seong-Tae, Eun-Ik Yang, and Joong-Cheol Choi. 2005. "Effect of Specimen Sizes, Specimen Shapes, and Placement Directions on Compressive Strength of Concrete." Nuclear Engineering and Design 236 (2):115-127. doi: http://dx.doi.org/10.1016/j.nucengdes.2005.08.004.

[21]Zheng, Jianlong, and Tuo Huang. 2015. "Study on Triaxial Test Method and Failure Criterion of asphalt Mixture." Journal of Traffic and Transportation Engineering (English Edition) 2 (2):93-106. doi: http://dx.doi.org/10.1016/j.jtte.2015.02.003.

16 $^{\text {th }}$ LACCEI International Multi-Conference for Engineering, Education, and Technology: "Innovation in Education and Inclusion", 18-20 July 2018, Lima, Peru. 